\title{
The Diagnosis of Growth Hormone Deficiency in Adults
}

\author{
Ken K. Y Ho and David M. Hoffman \\ Garvan Institute of Medical Research, St. Vincent's Hospital, Sydney, NSW, Australia
}

Key words: GH deficiency, insulin tolerance test, insulin-like growth factor-I

\section{Introduction}

Adults with GH deficiency (GHD) have a recognisable syndrome of increased adiposity, reduced lean tissue mass and bone mineral, diminished exercise tolerance and impaired psychological well-being (1). However, neither the abnormalities of body composition and function, nor the overall features of the syndrome is sufficiently distinctive to enable a confident diagnosis of GH deficiency. Biochemical tests therefore remain necessary for diagnosis. Since GH secretion decreases with aging and is reduced by obesity (2), both these factors must be controlled for in an evaluation of diagnostic methods for GH deficiency.

\section{Comparison of Diagnostic Tests}

From an evaluation of the merits of the insulin tolerance test (ITT), mean $24 \mathrm{~h} \mathrm{GH}$ concentration (IGHC, derived from repetitive sampling every $20 \mathrm{~min}$ ), IGF-I and IGFBP-3, we have previously reported that the ITT was the only test capable of distinguishing patients with organic GHD from normal subjects matched for age, sex and BMI (3) (Fig. 1). The sensitivity of

Correspondence: Dr. Ken Y. Ho, Garvan Institute of Medical Research, St. Vincent's Hospital, 384 Victoria St., Sydney, NSW 2010, Australia the GH RIA used in our study $(0.2 \mu \mathrm{g} / \mathrm{L})$ limited the utility of IGHC since $16 \%$ of normal subjects as well as $80 \%$ of hypopituitary subjects had "undetectable" values. Using a GH ELISA with 2 order greater sensitivity $(1 \mathrm{ng} / \mathrm{L})(4,5)$, we found that (i) IGHC was detectable in all GHD and normal subjects and (ii) there was a better but still incomplete separation of values between hypopituitary and normal subjects (iii) there was a significant correlation between IGHC and IGF-I, a relationship not demonstrable when $\mathrm{GH}$ was measured by RLA but showing that IGHC accounted for only $50 \%$ of the IGF-1 variance.

In the same study IGF-1 and IGFBP3 were also of limited diagnostic value because of a marked overlap in values between the hypopituitary and normal subjects, and hence low sensitivity (3). This finding can be explained by the above observation that circulating IGF-1 in GHD and normal subjects may be dependent on factors other than GH. A review of recent reports indicates overall sensitivities for IGF-I and IGFBP-3 of about $50 \%$ and $30 \%$, respectively. More recently, we have found that measurement of the acid-labile subunit, ALS, of the IGF/IGFBP3 complex has a similar limited sensitivity to IGF-I in the diagnosis of GHD.

\section{Evaluation of Diagnostic Tests}

According to Bayes' theorem, the ability of a test to correctly identify the presence of dis- 

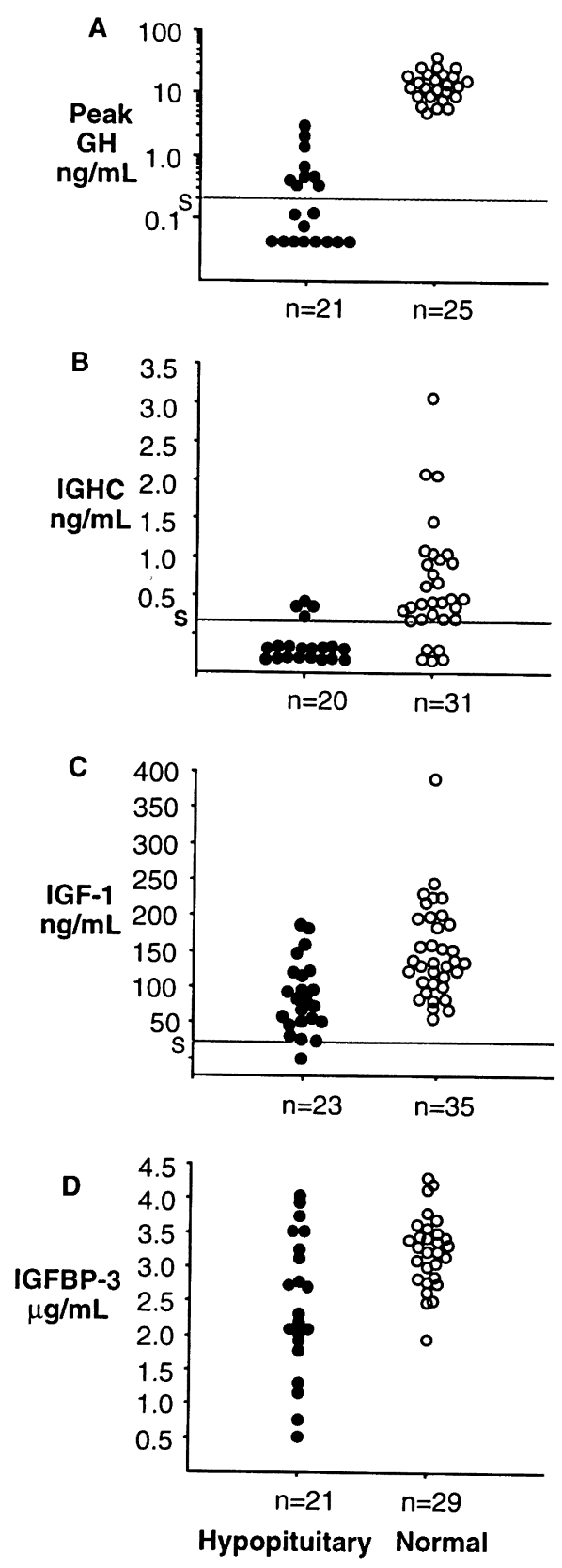

Fig. 1 Comparison of (A) peak GH response to insulin tolerance test, (B) $24 \mathrm{~h}$ integrated $\mathrm{GH}$ concentration (IGHC), (C) IGF-1 and (D)IGFBP-3 levels in hypopituitary (O) and normal $(\bigcirc)$ subjects matched for sex, age and body mass index. Data are derived from Hoffman et al. (3).

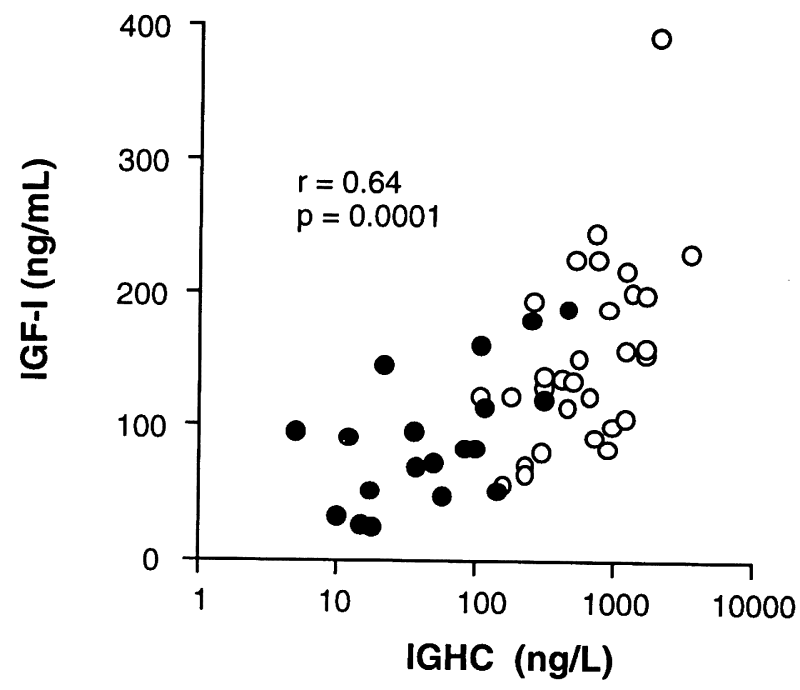

Fig. 2 Relationship between IGF-1 and integrated $\mathrm{GH}$ concentration (IGHC) in GH deficient $(\bigcirc)$ and normal $(\bigcirc)$ subjects as measured by a supersensitive ELISA. Data are derived from Reutens et al. (4).

ease (positive predictive value, PPV) depends on the prior probability of disease in the population tested. On the basis of a recent Swedish study we can estimate the prevalence of organic GHD in the general population to be less than $0.02 \%$ (6). In contrast, up to $80 \%$ of patients with known pituitary disease attending an endocrine department outpatient clinic have organic GHD $(7,8)$. Based on current knowledge of sensitivity, specificity and prior probability of disease, the PPV of the ITT in patients with a history of pituitary disease is $99 \%$, but less than $1 \%$ in the general population. We emphasise that although reliable in adults this test is not reliable in children because of the marked dependence of the GH response on sexual maturation (9). The ITT, although uncomfortable, is a safe test when performed in adults in an experienced endocrine unit (10). The diagnostic potential of other tests of GH stimulation needs to be systematically evaluated and should not be extrapolated from that obtained from the ITT since the GH stimulatory capacity differs between 
different agents (11). Newer potent provocative agents currently under investigation such as $\mathrm{GH}$ releasing peptides (12) or combined pyridostigmine and GHRH, hold promise for the future as less stressful stimulation tests.

\section{Conclusion}

We conclude that GHD may be reliably diagnosed by the ITT, but should be undertaken only in adults with known or suspected pituitary disease. The merit of other stimulation tests should be investigated and not extrapolated from the ITT. IGF-1 and IGFBP-3 are unreliable indicators of GH deficiency.

\section{Acknowledgment}

This work was supported by Novo Nordisk and the NHMRC of Australia.

\section{References}

1. Cuneo RC, Salomon F, McGauley GA, Sonksen $\mathrm{PH}$. The growth hormone deficiency syndrome in adults. Clin Endocrinol 1992; 37: 387-97.

2. Ho KY, Evans WS, Blizzard RM, et al. Effects of sex and age on the 24-hour profile of growth hormone secretion in man: importance of endogenous estradiol concentrations. J Clin Endocrinol Metab 1987; 64 (1): 51-8.

3. Hoffman DM, O'Sullivan AJ, Baxter RC, Ho KY. Diagnosis of growth hormone deficiency in adults. Lancet 1994; 343: 1064-8.

4. Reutens AT, Hoffman DM, Leung K, Ho KKY. Evaluation and application of a highly sensitive assay for growth hormone (GH) in the study of adult GH deficiency. J Clin Endocrinol Metab
1995; 80 (2): 480-5.

5. Reutens AT, Veldhuis JD, Hoffman DM, Leung $\mathrm{KC}$, Ho KKY. A highly sensitive growth hormone (GH) assay uncovers increased contribution of a tonic mode of GH secretion in adults with organic GH deficiency. J Clin Endocrinol Metab 1996; 81: 1591-7.

6. Rosen T, Bengtsson BA. Epidemiology of adult onset hypopituitarism in Goteborg, Sweden during 1956-1987. 18th International Symposium: Growth hormone and growth factors in endocrinology and metabolism. 1994: 60 (Abstr A3).

7. Weissberger AJ, Verkikiou K, Sonksen PH. Diagnosis of growth hormone deficiency in adults. Lancet 1994; 344: 483.

8. Toogood AA, Beardwell CG, Shalet SM. The severity of growth hormone deficiency in adults with pituitary disease is related to the degree of hypopituitarism. Clin Endocrinol 1994; 41: 511-6.

9. Marin G, Domene HM, Barnes KM, Blackwell BJ, Cassorla FG, Cutler Jr GB. The effects of estrogen priming and puberty on the growth hormone response to standardized treadmill exercise and arginine-insulin in normal girls and boys. J Clin Endocrinol Metab 1994; 79: 537-41.

10. Jones SL, Trainer PJ, Perry L, Wass JAH, Besser GM, Grossman A. An audit of the insulin tolerance test in adult subjects in an acute investigation unit over one year. Clin Endocrinol 1994; 41: 123-8.

11. Lin T, Tucci JR. Provocative tests of growth-hormone release. A comparison of results with seven stimuli. Ann Intern Med 1974; 80: 464-9.

12. Bowers CY, Reynolds GA, Durham D, Barrera CM, Pezzoli SS, Thorner MO. Growth hormone (GH)-releasing peptide stimulates $\mathrm{GH}$ release in normal men and acts synergistically with GHreleasing hormone. J Clin Endocrinol Metab 1990; 70 (4): 975-82. 